\title{
Inflammation-based Prognostic Score as a Prognostic Biomarker in Patients With Recurrent and/or Metastatic Head and Neck Squamous Cell Carcinoma Treated With Nivolumab Therapy
}

\author{
MIOKO MATSUO ${ }^{1}$, RYUJI YASUMATSU ${ }^{1}$, MUNEYUKI MASUDA $^{2}$, SATOSHI TOH ${ }^{2}$, TAKAHIRO WAKASAKI ${ }^{1}$, \\ KAZUKI HASHIMOTO $^{1}$, RINA JIROMARU ${ }^{1}$, TOMOMI MANAKO $^{1}$ and TAKASHI NAKAGAWA ${ }^{1}$ \\ ${ }^{1}$ Department of Otorhinolaryngology, Graduate School of Medical Sciences, Kyushu University, Fukuoka, Japan; \\ ${ }^{2}$ Department of Head and Neck Surgery, National Hospital Organization Kyushu Cancer Center, Fukuoka, Japan
}

\begin{abstract}
Background/Aim: The inflammation-based prognostic score (IBPS) has attracted attention recently as a prognostic biomarker for head and neck cancer patients. However, as the IBPS often changes after anticancer drug therapy, its independent prognostic value remains controversial. We aimed to investigate the relationship between the IBPS and prognosis in recurrent and/or metastatic head and neck squamous cell carcinoma (RMHNSCC) treated with nivolumab, and investigate changes in the IBPS before and after nivolumab treatment. Patients and Methods: Total of 164 patients with RMHNSCC received nivolumab therapy were retrospectively analyzed. Results: Univariate analysis among the 164 patients revealed that the performance status (PS), immune-related adverse event (irAE) status, pre- and post-therapy Glasgow Prognostic Score (GPS), neutrophil-to-lymphocyte ratio $(N L R), C$-reactive protein-to-albumin ratio $(C A R)$, plateletto-lymphocyte ratio $(P L R)$, and post-eosinophil count, were all significant predictors of overall survival $(O S)(p<0.05)$. A multivariate analysis revealed that PS, irAEs, post-GPS, post-NLR, post-CAR, and post-eosinophil count were independent prognostic factors for overall survival. Conclusion: Post-treatment factors were identified as
\end{abstract}

This article is freely accessible online.

Correspondence to: Ryuji Yasumatsu, Department of Otorhinolaryngology, Graduate School of Medical Sciences, Kyushu University, 3-1-1 Maidashi, Higashi-ku, Fukuoka 812-8582, Japan. Tel: +81 926425668, Fax: +81 926425685; e-mail: yasumatsu.ryuji.847@m.kyushu-u.ac.jp

Key Words: Head and neck squamous cell carcinoma, biomarker, IBPS, nivolumab. independent prognostic factors for RMHNSCC and can more accurately predict prognosis compared to nivolumab-treated RMHNSCC pre-treatment factors.

In the past decade, new anticancer agents have led to an improved survival for recurrent and/or metastatic head and neck squamous cell carcinoma (RMHNSCC). The antiEGFR antibody cetuximab and the immune checkpoint inhibitors (ICIs), nivolumab/pembrolizumab, are new types of palliative anti-cancer drug therapy for patients with RMHNSCC (1-3) with positive outcomes.

Due to such an increase in options available for anti-cancer drug therapy, it has become more important than ever to establish an approach to select the most effective drugs for each patient. In recent years, biomarkers, such as the ones predicting patient's responses to a particular treatment as well as the ones predicting the course of the disease, have been garnering attention for the evaluation of cancer drug selection (4). Widely known predictive markers include pathological factors, such as programmed cell death 1- ligand 1 (PDL-1) and epidermal growth factor receptor (EGFR), and their values can be used to infer, to some extent, which drugs will be effective or ineffective $(5,6)$. Vital signs, such as the Eastern Cooperative Oncology Group performance status (PS) and staging systems, using image data and blood sample analysis, are also known as biomarkers, in a broad sense (4). These are biological factors independent of pathological characteristics and play a large role as prognostic biomarkers. In particular, the inflammation-based prognostic score (IBPS), which is obtained from hematological biomarkers based on the systemic inflammatory response (SIR), has been attracting attention in recent years as a prognostic biomarker for cancer patients $(7,8)$.

In previous studies (9-16), information obtained from hematological biomarkers, including the IBPS, demonstrated 
their usefulness as prognostic factors for HNSCC. A number of prognostic values, such as the Glasgow Prognostic Score (GPS) (9), neutrophil-to-lymphocyte ratio (NLR) $(10,11)$, C-reactive protein (CRP)-to-albumin ratio (CAR) (12), platelet-to-lymphocyte ratio (PLR) $(13,14)$, and eosinophil count $(15,16)$ associated with the systemic inflammatory response in cancer patients, have been established, and a high GPS, NLR, CAR, and PLR and a low eosinophil count have been reported to be related to poor prognosis in cancer patients (9-16). However, the levels of inflammatory markers reportedly change during treatment (17).

In the present study, we investigated the relationship between the IBPS, including the GPS, NLR, CAR, PLR, and eosinophil count, and the overall survival (OS) in RMHNSCC patients treated with nivolumab. Furthermore, we also examined the changes in the IBPS after nivolumab administration to assess the impact nivolumab treatment has on the IBPS.

\section{Patients and Methods}

Patients. A total 164 patients with RMHNSCC, who received nivolumab therapy from April 2017 to March 2020, were retrospectively analyzed. Nivolumab was continued until progression of disease or occurrence of a severe adverse event.

Follow-up of patients lasted till the data cut-off point (June 30, 2021 ) or death. The median follow-up interval was 12.6 months (range $=0.3-51.2$ months).

This study conformed to the principles of the Declaration of Helsinki and was approved by the institutional review board of Kyushu University (approval number: 2021-138) and Kyushu Cancer Center (approval number: 2019-58). All patients provided written informed consent for the study.

Relevant evaluations. Blood samples were obtained within 1 week before nivolumab administration (pre) and 8 weeks after its administration (post). To estimate the GPS, we used a three-grade evaluation as follows: i) CRP $>1.0 \mathrm{mg} / \mathrm{dl}$ and albumin $<3.5 \mathrm{~g} / \mathrm{dl}$ were considered GPS 2, ii) CRP $>1.0 \mathrm{mg} / \mathrm{dl}$ or albumin $<3.5 \mathrm{~g} / \mathrm{dl}$ were considered GPS 1 , and iii) CRP $\leq 1.0 \mathrm{mg} / \mathrm{dl}$ and albumin $\geq 3.5 \mathrm{~g} / \mathrm{dl}$ were considered GPS 0 (18). The NLR was calculated as the neutrophil count divided by the lymphocyte count, CAR was calculated as the CRP level divided by the albumin level, and the PLR was calculated as the platelet count divided by the lymphocyte count.

Patients who relapsed within 6 months after platinum-based drug therapy were considered platinum-resistant; otherwise, patients were considered platinum-sensitive.

Nivolumab was administered to the patients at a dose of $3 \mathrm{mg} / \mathrm{kg}$ or $240 \mathrm{mg} /$ body every 2 weeks. Immune-related adverse events (irAEs) that were induced by nivolumab were assessed by the Common Terminology Criteria for Adverse Events (CTCAE), version 5.0.

The OS was assessed from the first day of nivolumab administration to death or the date of the analysis (June 30,2021), if the patients were alive. The progression-free survival (PFS) was assessed from the first day of nivolumab to the date of disease progression or death.
Table I. Patient characteristics at time of study initiation.

\begin{tabular}{lc}
\hline Characteristics & $\begin{array}{c}\text { Number of patients (\%) } \\
\text { Total }(\mathrm{n}=164)\end{array}$ \\
\hline Gender & \\
Male & $127(77.4)$ \\
Female & $37(22.6)$ \\
Age & \\
$<75$ years & $140(85.4)$ \\
$\geq 75$ years & $24(14.6)$ \\
Median (range) & $65.0(23-87)$ \\
ECOG & \\
PS 0-1 & $145(88.4)$ \\
PS 2-4 & $19(11.6)$ \\
Primary site & \\
Nasopharynx & $7(4.3)$ \\
Oropharynx & $28(17.1)$ \\
Hypopharynx & $39(23.8)$ \\
Larynx & $11(6.7)$ \\
Oral cavity & $47(28.6)$ \\
Sinonasal truct & $21(12.8)$ \\
External auditory canal & $9(5.5)$ \\
Others (Salivary gland \& primary unknown) & $2(1.2)$ \\
Platinum & \\
Sensitive & $52(31.7)$ \\
Resistant & $112(68.3)$ \\
Tumor localization & \\
Locoregional ( \pm distant metastasis) & $116(70.7)$ \\
Distant metastasis only & $48(29.3)$ \\
Immune-related adverse events & \\
+ & $52(31.7)$ \\
- & $112(68.3)$ \\
\hline & \\
\hline & \\
&
\end{tabular}

ECOG: Eastern Cooperative Oncology Group; PS: performance status.

Statistical analysis. All calculations were performed using the SPSS statistics software program, ver. 22.0 (IBM Japan, Ltd., Tokyo, Japan). We calculated the optimal cut-off values of the NLR, CAR, PLR, and eosinophil count, based on a receiver operating curve (ROC) analysis. Patients were classified into high and low groups, based on each cut-off value, and investigated at two points: i) preand ii) post-nivolumab treatment. The OS and PFS were calculated using the Kaplan-Meier method and were evaluated with the logrank test. Univariate and multivariate Cox proportional hazards regression models were used to assess the associations between potential confounding variables and the OS. Differences with a $p$ Value less than 0.05 were considered significant.

\section{Results}

Patient characteristics. The clinical characteristics of the patients are summarized in Table I. The median age at nivolumab therapy was 65.0 (range $=23-87$ ) years old, and most patients were male $(77.4 \%)$ with a PS of 0 or 1 (collectively, 88.4\%).

Of the 164 patients, $52(31.7 \%)$ were platinum-sensitive, whereas 112 (68.3\%) were platinum-resistant. Recurrence or 

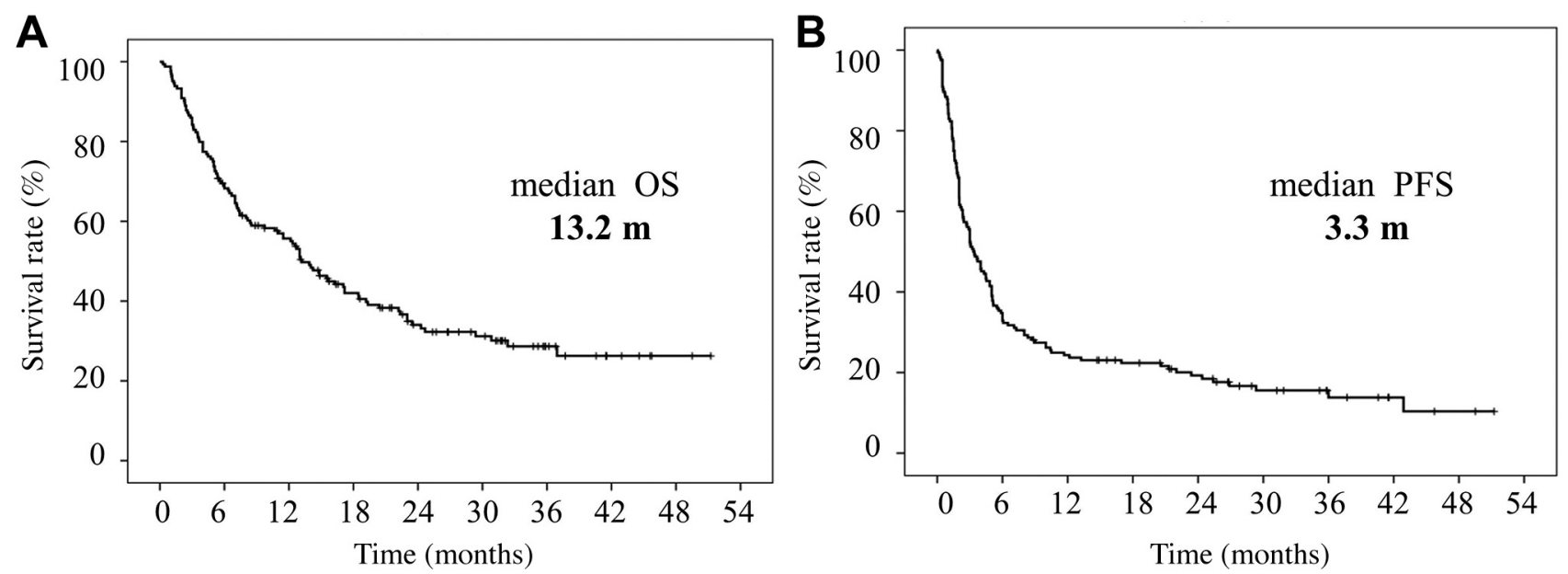

Figure 1. Kaplan-Meier curves. (A) Overall survival (OS) and (B) progression-free survival (PFS) of patients with head and neck squamous cell carcinoma who received nivolumab therapy. $m$ : Months.
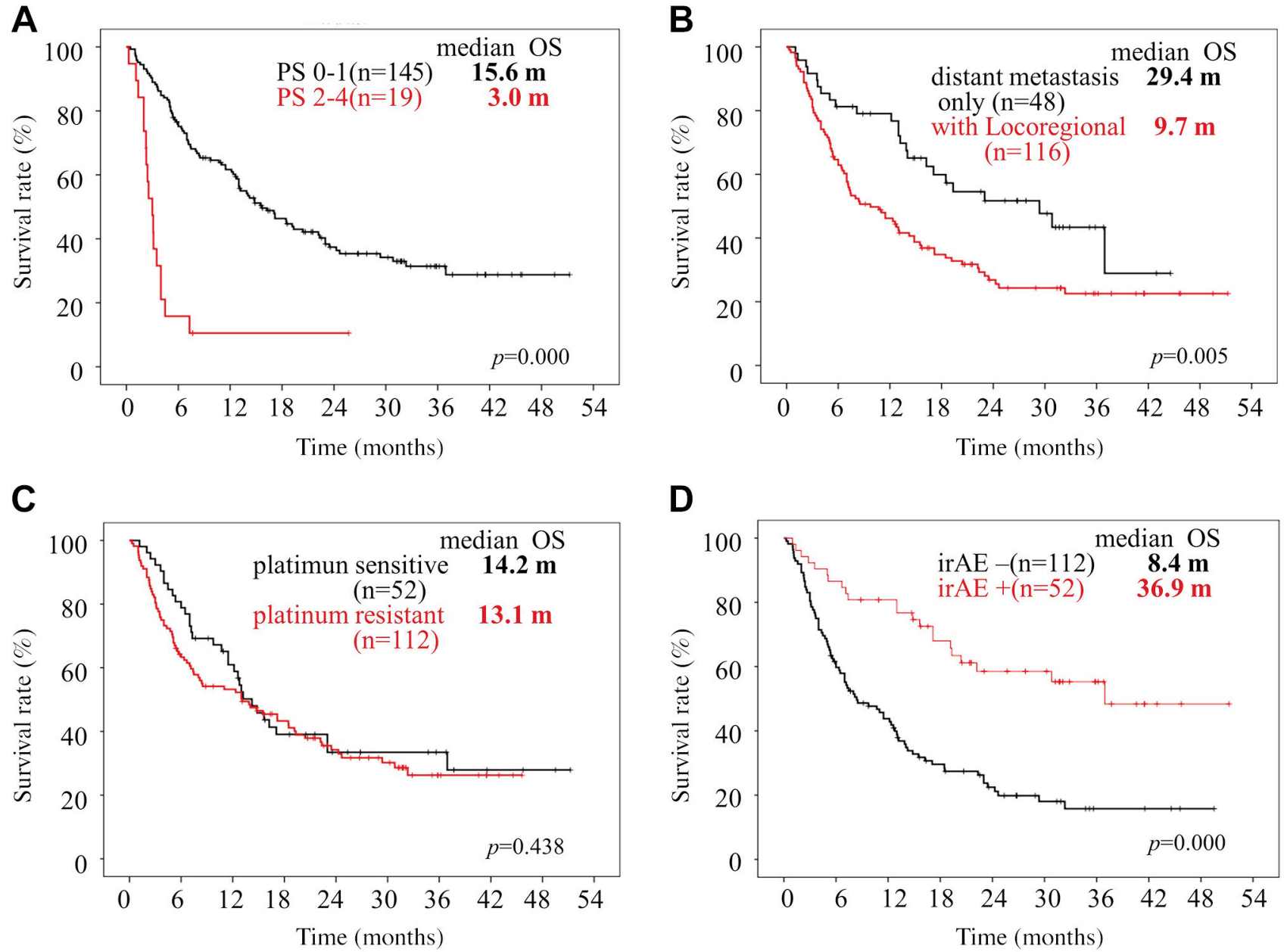

Figure 2. Kaplan-Meier curves of overall survival of patients with head and neck squamous cell carcinoma who received nivolumab therapy. Overall survival (OS) curves according to performance status (PS) (A), site of recurrence (B), platinum-refractory status $(C)$ and occurrence of immunerelated adverse events (irAEs) (D). m: Months. 

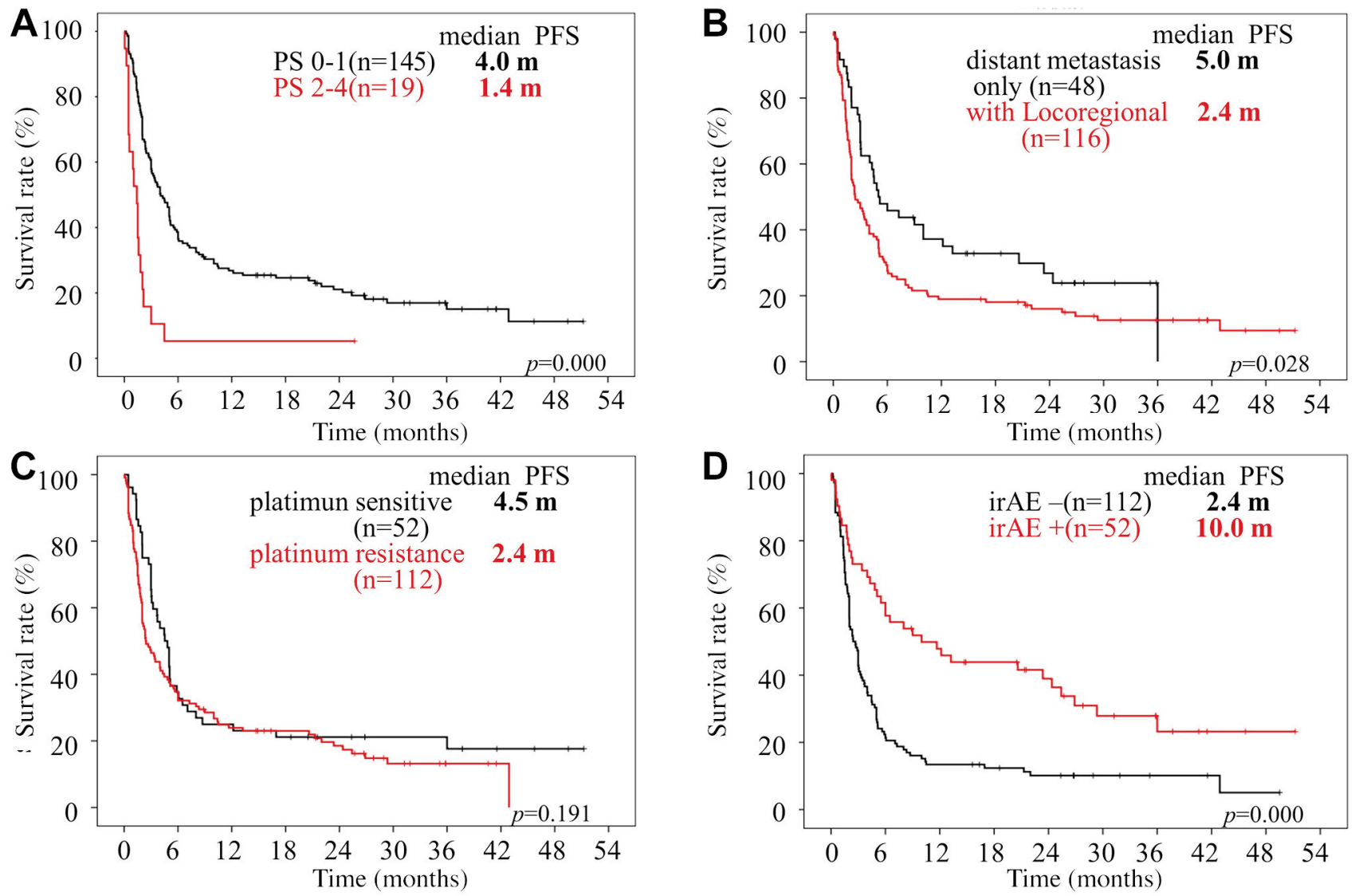

Figure 3. Kaplan-Meier curves of progression-free survival of patients with head and neck squamous cell carcinoma who received nivolumab therapy. Progression-free survival (PFS) curves according to performance status (PS) (A), site of recurrence (B), platinum-refractory status $(C)$ and occurrence of immune-related adverse events (irAEs) (D). m: Months.

metastasis at locoregional and distant sites was confirmed in $116(70.7 \%)$ and $48(29.3 \%)$, respectively. At the time of the analysis, $52(31.7 \%)$ of the 164 patients had developed irAEs.

Treatment response and survival outcome. The best overall response was determined in 164 patients with evaluable lesions. A complete response (CR) was observed in 18 patients (11.0\%), a partial response (PR) was observed in 34 patients $(20.7 \%)$, and stable disease (SD) was observed in 24 patients $(14.6 \%)$. The objective response rate (ORR) which corresponded to CR and PR was observed in 52 patients $(31.7 \%)$. The median OS was 13.2 months, and the median PFS was 3.3 months (Figure 1).

Cut-off values of the IBPS factors. According to ROC curves, the areas under the curve (AUCs) and 95\% confidence intervals (CIs) of the pre-nivolumab NLR, CAR, PLR, and eosinophil count were: i) $0.663 \quad(95 \% \mathrm{CI}=0.578-0.747$, $p=0.001)$, ii) $0.712(95 \% \mathrm{CI}=0.629-0.795, p=0.000)$, iii) 0.607 $(95 \% \mathrm{CI}=0.520-0.695, p=0.025)$, and iv) $0.530(95 \% \mathrm{CI}=0.436-$ $0.623, p=0.533)$, respectively. The optimal cut-off value was i)
6.505 for the pre-NLR, ii) 0.085 for the pre-CAR, iii) 319.84 for the pre-PLR, and iv) $97 / \mu$ for the pre-eosinophil count. The AUCs and 95\%CIs of the post-nivolumab NLR, PLR, CAR, and eosinophil count were: i) 0.779 (95\% CI=0.709-0.848, $p=0.000)$, ii) $0.828(95 \% \mathrm{CI}=0.763-0.892, p=0.000)$, iii) 0.631 $(95 \% \mathrm{CI}=0.546-0.716, p=0.006)$, and iv) $0.560(95 \% \mathrm{CI}=0.471-$ $0.649, p=0.211$ ), respectively. The optimal cut-off value was 6.351 for the post-NLR, 0.120 for the post-CAR, 430.660 for the post-PLR, and $120.500 / \mu$ for the post-eosinophil count.

The patients were classified into three groups of GPS $(0$, 1, and 2), and either Low or High groups, based on the cutoff values of the NLR, CAR, PLR, and eosinophil count preand post-nivolumab administration.

Survival analyses according to clinical and IBPS factors prenivolumab therapy. Patients with PS 0-1 had a significantly better OS and PFS $(p<0.05)$ compared to those with PS 2 to 4. Patients with distant metastasis had a significantly better OS and PFS $(p<0.05)$ compared to those with locoregional recurrence (Figure $2 \mathrm{~A}$ and $\mathrm{B}$, Figure $3 \mathrm{~A}$ and $\mathrm{B}$ ). 
Table II. Univariate and multivariate analysis of clinical factors and inflammation-based prognostic score associated with the overall survival.

\begin{tabular}{|c|c|c|c|c|c|c|c|c|c|}
\hline \multirow[b]{3}{*}{ Pre-treatment factor } & \multicolumn{4}{|c|}{ Overall survival } & \multirow[b]{3}{*}{ Post-treatment factor } & \multicolumn{4}{|c|}{ Overall survival } \\
\hline & \multicolumn{2}{|c|}{ Univariate analysis } & \multicolumn{2}{|c|}{ Multivariate analysis } & & \multicolumn{2}{|c|}{ Univariate analysis } & \multicolumn{2}{|c|}{ Multivariate analysis } \\
\hline & HR (95\%CI) & $p$-Value & HR (95\%CI) & $p$-Value & & HR (95\%CI) & $p$-Value & HR (95\%CI) & $p$-Value \\
\hline $\begin{array}{l}\text { ECOG } \\
\qquad \text { PS 0-1 }(\mathrm{n}=145) \\
\text { PS 2-4 }(\mathrm{n}=19)\end{array}$ & $\begin{array}{c}2.367 \\
(1.763-3.178)\end{array}$ & 0.000 & $\begin{array}{c}1.417 \\
(1.034-1.941)\end{array}$ & 0.030 & $\begin{array}{l}\text { IrAEs } \\
\quad+(\mathrm{n}=52) \\
\quad-(\mathrm{n}=112)\end{array}$ & $\begin{array}{c}0.335 \\
(0.208-0.537)\end{array}$ & 0.000 & $\begin{array}{c}0.414 \\
(0.251-0.683)\end{array}$ & 0.001 \\
\hline $\begin{array}{l}\text { Platinum } \\
\text { Sensitive }(\mathrm{n}=52) \\
\text { Resistant }(\mathrm{n}=112)\end{array}$ & $\begin{array}{c}1.176 \\
(0.780-1.773)\end{array}$ & 0.438 & - & - & & & & & \\
\hline $\begin{array}{l}\text { Locoregional }(\mathrm{n}=116) \\
( \pm \text { distant metastasis }) \\
\text { Distant metastasis } \\
\text { only }(\mathrm{n}=48)\end{array}$ & $\begin{array}{c}1.934 \\
(1.226-3.048)\end{array}$ & 0.005 & - & - & & & & & \\
\hline $\begin{array}{l}\text { (pre) GPS } \\
0(\mathrm{n}=83) \\
1(\mathrm{n}=51) \\
2(\mathrm{n}=30)\end{array}$ & $\begin{array}{c}1.774 \\
(1.397-2.252)\end{array}$ & 0.000 & - & - & $\begin{array}{r}\text { (post) GPS } \\
0(\mathrm{n}=73) \\
1(\mathrm{n}=40) \\
2(\mathrm{n}=51)\end{array}$ & $\begin{array}{c}2.836 \\
(2.237-3.595)\end{array}$ & 0.000 & $\begin{array}{c}1.801 \\
(1.336-2.429)\end{array}$ & 0.000 \\
\hline $\begin{array}{l}\text { (pre) NLR } \\
\text { (Cut off value 6.505) }\end{array}$ & 2.599 & 0.000 & - & - & (post) NLR & 5.159 & 0.000 & 2.117 & 0.002 \\
\hline $\begin{array}{l}\text { Low }(\mathrm{n}=103) \\
\text { High }(\mathrm{n}=61)\end{array}$ & $(1.773-3.810)$ & & & & $\begin{array}{l}\text { Low }(\mathrm{n}=94) \\
\text { High }(\mathrm{n}=70)\end{array}$ & $(3.448-7.720)$ & & $(1.309-3.423)$ & \\
\hline $\begin{array}{l}\text { (pre) CAR } \\
\text { (Cut off value 0.085) } \\
\text { Low }(\mathrm{n}=69) \\
\text { High }(\mathrm{n}=95)\end{array}$ & $\begin{array}{c}2.575 \\
(1.693-3.916)\end{array}$ & 0.000 & - & - & $\begin{array}{l}\text { (post) CAR } \\
\text { Low }(n=62) \\
\text { High }(n=102)\end{array}$ & $\begin{array}{c}6.626 \\
(3.978-11.036)\end{array}$ & 0.000 & $\begin{array}{c}3.246 \\
(1.699-6.200)\end{array}$ & 0.000 \\
\hline $\begin{array}{l}\text { (pre) PLR } \\
\text { (Cut off value } 319.84) \\
\text { Low }(\mathrm{n}=69) \\
\text { High }(\mathrm{n}=95)\end{array}$ & $\begin{array}{c}2.019 \\
(1.351-3.017)\end{array}$ & 0.001 & - & - & $\begin{array}{l}\text { (post) PLR } \\
\text { Low }(n=120) \\
\text { High }(n=44)\end{array}$ & $(2.226-5.019)$ & 0.000 & - & - \\
\hline $\begin{array}{l}\text { (pre) Eosinophil } \\
\text { (cut off value 97.0) } \\
\text { Low }(n=89) \\
\text { High }(n=75)\end{array}$ & $\begin{array}{c}0.795 \\
(0.543-1.164)\end{array}$ & 0.239 & - & - & $\begin{array}{l}\text { (post) Eosinophil } \\
\text { Low }(\mathrm{n}=68) \\
\text { High }(\mathrm{n}=96)\end{array}$ & $\begin{array}{c}0.562 \\
(0.384-0.821)\end{array}$ & 0.003 & $\begin{array}{c}0.334 \\
(0.217-0.514)\end{array}$ & 0.000 \\
\hline
\end{tabular}

CAR: C-reactive protein (CRP)-to-albumin ratio; ECOG: Eastern Cooperative Oncology Group; GPS: Glasgow Prognostic Score; HR: hazard ratio; IrAEs: immune-related adverse events; NLR: neutrophil-to-lymphocyte ratio; PLR: platelet-to-lymphocyte ratio. Significant $p$-Values are shown in bold.

The median OS was i) 19.3 , ii) 8.4 , and iii) 3.7 months for pre-GPS 0,1 , and 2 , respectively, showing significant differences in the OS among them $(p=0.000)$. The survival results were also significantly different between the preNLR $(p=0.000)$, pre-CAR $(p=0.000)$, and pre-PLR groups $(p=0.001)$. However, the pre-eosinophil count failed to show a significant prognostic role $(p=0.239)$ (Figure $4 \mathrm{~A}, \mathrm{C}$, E, and $\mathrm{G}$ ).

There were no significant differences in the OS or PFS between the platinum-sensitive and platinum-resistant groups (Figure 2C and Figure 3C).

Survival analyses according to clinical and IBPS factors postnivolumab therapy. Patients with irAEs had a significantly better OS and PFS $(p<0.05)$ compared to those without irAEs (Figure 2D and Figure 3D).
The median OS was not reached at 11.5 and 3.7 months for none of the groups with post-GPS status 0,1 or 2 $(p=0.000)$, showing significant differences in OS among them $(p=0.000)$. The survival results were also significantly different between the post-NLR $(p=0.000)$, post-CAR $(p=0.000)$, post-PLR $(p=0.000)$, and post-eosinophil count groups $(p=0.003)$ (Figure 4B, D, F, H, and J).

Univariate and multivariate analyses according to the preand post-treatment clinical and IBPS factors. Univariate analyses revealed that the i) PS, ii) tumor localization, iii) irAE status, and iv) pre- and post-GPS, NLR, CAR, and PLR and post-eosinophil count were all significant predictors of the OS. A multivariate analysis revealed that the i) PS [hazard ratio $(\mathrm{HR})=1.417(95 \% \mathrm{CI}=1.034-1.941), p=0.030]$, ii) irAEs $[\mathrm{HR}=0.414(95 \% \mathrm{CI}=0.251-0.683), p=0.001]$, iii $)$ post-GPS 

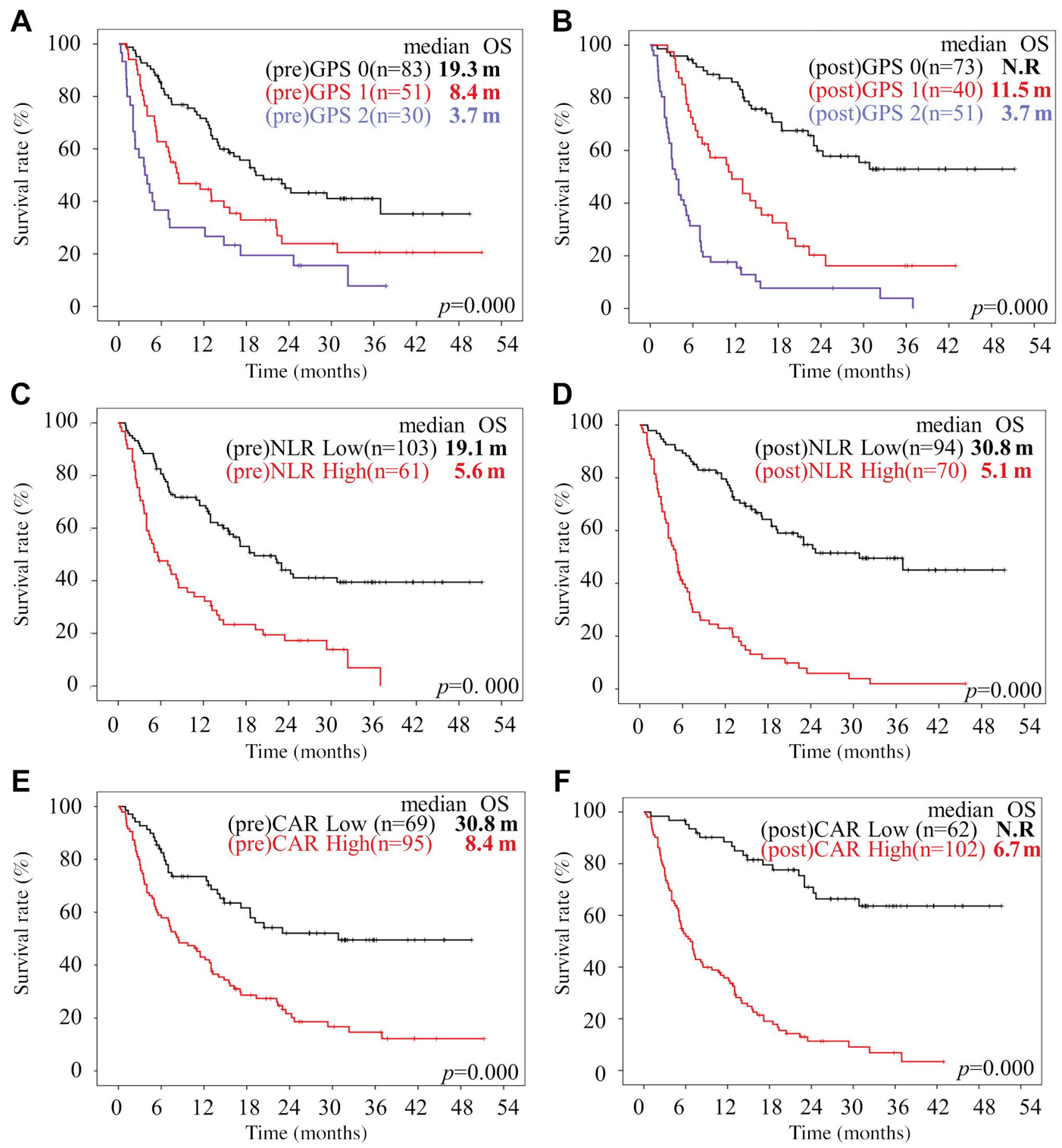

Figure 4. Continued

[HR=1.801 (95\%CI=1.336-2.429), $p=0.000]$, iv) post-NLR [HR=2.117 (95\%CI: 1.309-3.423), $p=0.002], \mathrm{v})$ post-CAR $[\mathrm{HR}=3.246(95 \% \mathrm{CI}=1.699-6.200), p=0.000]$, and vi) posteosinophil count $[\mathrm{HR}=0.334(95 \% \mathrm{CI}=0.217-0.514), p=0.000]$ were independent prognostic factors for the OS (Table II).

Changes in the IBPS after nivolumab administration. Following nivolumab treatment the prognosis changed from poor to good in $13 \%$ of pre-GPS from scores 1 and $2(22 / 164$ patients), $10 \%$ of pre-NLR-high (17/164 patients), $12 \%$ of pre-CAR-high (20/164 patients), $37 \%$ of pre-PLR-high 

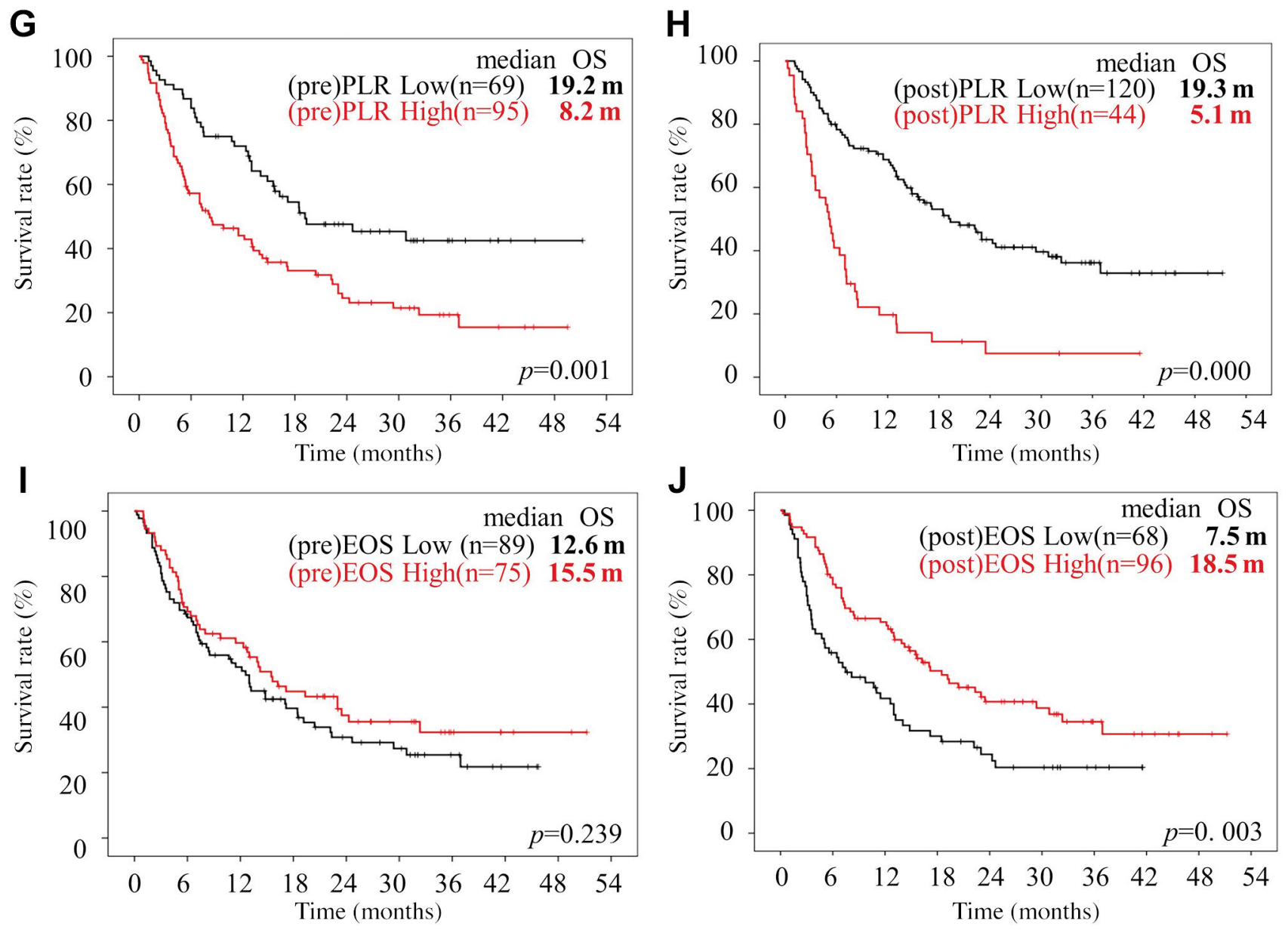

Figure 4. Kaplan-Meier curves of overall survival of patients with head and neck squamous cell carcinoma treated with nivolumab. Overall survival $(O S)$ curves according to Glasgow Prognostic Score $(G P S)(A, B)$, neutrophil-to-lymphocyte ratio $(N L R)(C, D), C$-reactive protein $(C R P)$-to-albumin ratio $(C A R)(E, F)$, platelet-to-lymphocyte ratio $(P L R)(G, H)$ and eosinophil $(E O S)$ count $(I, J)$. m: Months.

(60/164 patients), and $27 \%$ of pre-eosinophil count-low (44/164 patients) (Figure 5). On the other hand, a deterioration of prognosis was observed in $30 \%$ of pre-GPS from scores 0 and 1 (48/164 patients), 16\% of pre-NLR-low (26/164 patients), $16 \%$ of pre-CAR-low (26/164 patients), $5 \%$ of pre-PLR-low (9/164 patients), and $14 \%$ of preeosinophil count-high (23/164 patients).

Association between the IBPS factors nivolumab therapy and the incidence of irAEs. The total incidence of irAEs was $31.7 \%$ (52/164 patients). The incidence of irAEs in the poor prognosis group based on the pre-treatment IBPS (GPS 1-2, high-NLR/CAR/PLR, and low-eosinophil count) was low compared to the good prognosis group (GPS 0-1, lowNLR/CAR/PLR. high- eosinophil count). Notably, the incidence of irAEs differed significantly between the preNLR $(p=0.00001)$, pre-CAR $(p=0.042)$, and pre-PLR $(p=0.0002)$ groups (Table III).

\section{Discussion}

In this study, the median OS (13.2 vs. 7.5 months) and the median PFS (3.3 vs. 2.0 months) were favorable compared to those in the Checkmate 141 study by Ferris et al. (2). In addition, our results showed that nivolumab was more effective in patients with a PS status of 0 and 1 compared to those with PS 2 status. Other studies have suggested that a favorable PS is predictive of a better OS and PFS in melanoma and nonsmall-cell lung patients treated with ICIs $(19,20)$. This is consistent with previous findings. However, the ORR and OS were similar between the platinum-sensitive and -resistant groups in the present study, whereas Hori et al. have reported that platinum-resistant carcinoma is an independent negative predictor of both the PFS and OS (21). In general, rapid progression after platinum-containing chemotherapy has been shown to be associated with poor outcomes (22). Further largescale studies are, therefore, warranted. 


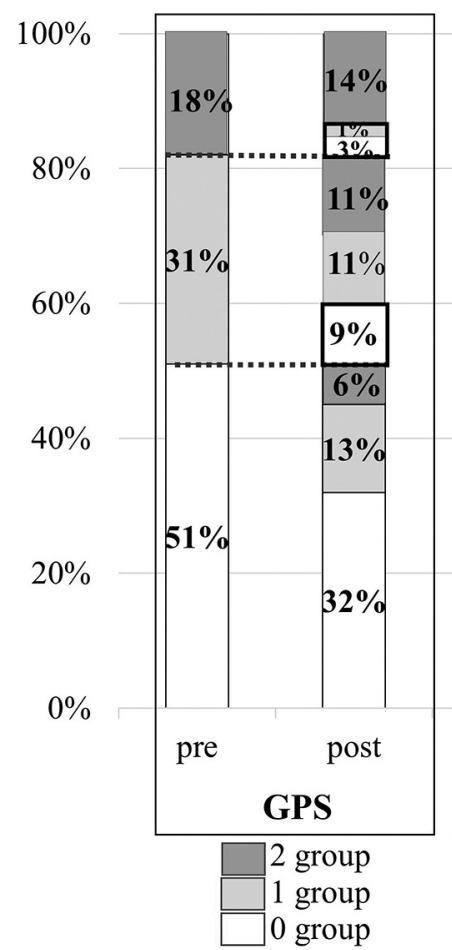

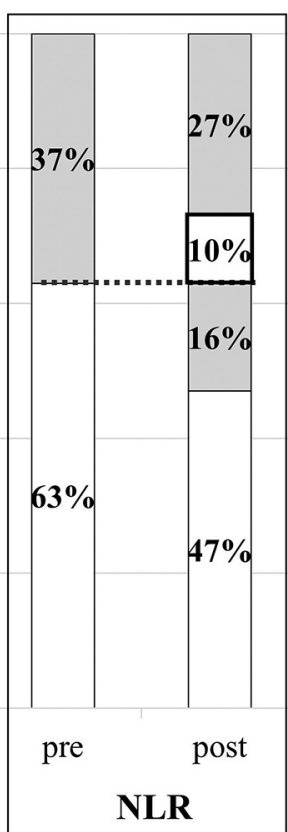

High group Low group

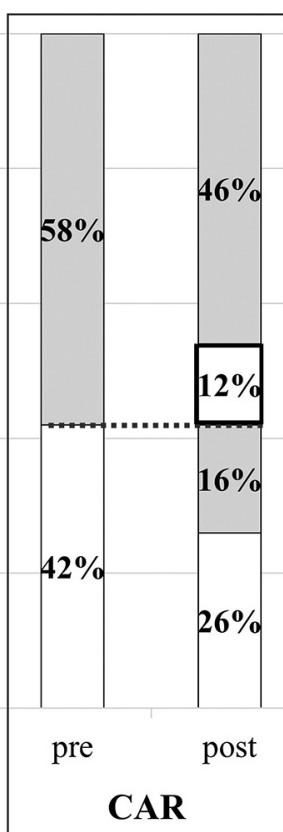

High group Low group

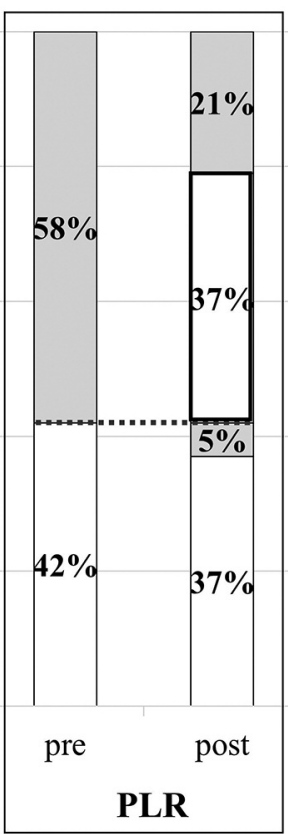

High group Low group

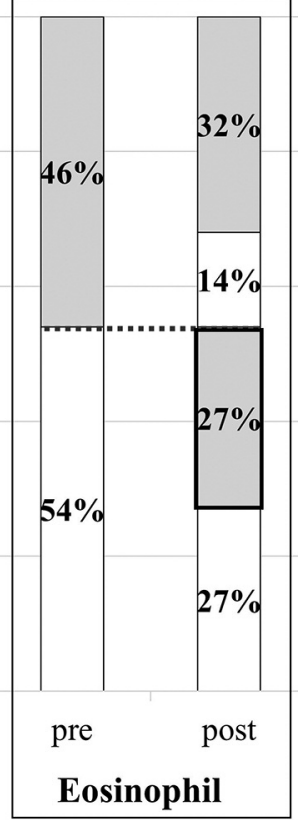

High group Low group

Figure 5. Changes in the IBPS after nivolumab administration according to Glasgow Prognostic Score (GPS), neutrophil-to-lymphocyte ratio (NLR), $C$-reactive protein (CRP)-to-albumin ratio (CAR), platelet-to-lymphocyte ratio (PLR) and eosinophil (EOS) count. m: Months.

Table III. Pre-inflammation-based prognostic score and incidence of adverse events.

\begin{tabular}{|c|c|c|c|c|c|c|c|c|c|c|c|}
\hline & $\begin{array}{c}\text { pre-GPS } \\
0\end{array}$ & $\begin{array}{c}\text { pre-GPS } \\
1\end{array}$ & $\begin{array}{c}\text { pre-GPS } \\
2\end{array}$ & $\begin{array}{l}\text { pre-NLR } \\
\text { High }\end{array}$ & $\begin{array}{l}\text { pre-NLR } \\
\text { Low }\end{array}$ & $\begin{array}{c}\text { pre-CAR } \\
\text { High }\end{array}$ & $\begin{array}{l}\text { pre-CAR } \\
\text { Low }\end{array}$ & $\begin{array}{c}\text { pre-PLR } \\
\text { High }\end{array}$ & $\begin{array}{l}\text { pre-PLR } \\
\text { Low }\end{array}$ & $\begin{array}{l}\text { pre-Eosinophil } \\
\text { Low }\end{array}$ & $\begin{array}{c}\text { pre-Eosinophil } \\
\text { High }\end{array}$ \\
\hline $\begin{array}{l}\mathrm{AE}^{*}+(\%) \\
\text { number } \\
p \text {-Value }\end{array}$ & $\begin{array}{c}32.5 \% \\
(27 / 83) \\
0.580\end{array}$ & $\begin{array}{c}37.3 \% \\
(19 / 51)\end{array}$ & $\begin{array}{l}20.0 \% \\
(6 / 30)\end{array}$ & $\begin{array}{c}22.6 \% \\
(7 / 61) \\
0.00001\end{array}$ & $\begin{array}{c}43.7 \% \\
(45 / 103)\end{array}$ & $\begin{array}{c}25.2 \% \\
(24 / 95) \\
0.042\end{array}$ & $\begin{array}{l}40.6 \% \\
(28 / 69)\end{array}$ & $\begin{array}{l}17.9 \% \\
(17 / 95) \\
0.0002\end{array}$ & $\begin{array}{l}50.7 \% \\
(35 / 69)\end{array}$ & $\begin{array}{c}34.8 \% \\
(31 / 89) \\
0.401\end{array}$ & $\begin{array}{l}28.0 \% \\
(21 / 75)\end{array}$ \\
\hline
\end{tabular}

AE: Adverse event; CAR: C-reactive protein (CRP)-to-albumin ratio; GPS: Glasgow Prognostic Score; NLR: neutrophil-to-lymphocyte ratio; IPLR: platelet-to-lymphocyte ratio.

In recent years, the usefulness of hematological factors, including the IBPS, as prognostic biomarkers, has been recognized across various types of cancer (23-27). The IBPS (NLR, PLR, CAR, GPS, eosinophil count) is a score calculated using the lymphocytes and eosinophils involved in tumor suppression and the neutrophils and platelets involved in tumor growth (28-31), either on their own or in combination. IBPS is an easily available and non-invasive prognostic biomarker, and is now widely recognized as a new prognostic biomarker for head and neck cancer as well (9-16, 32-37). Despite the benefits, most studies have only explored the relationship between the pre-treatment IBPS and the prognosis. The independent prognostic value of the IBPS, thus, remains controversial, as it often changes after anti-cancer drug therapy.
Interestingly, the IBPS 8 weeks following administration of nivolumab played a role as a reliable predictor of the OS in our study. We found that $20 \%$ to $60 \%$ of patients who belonged to the poor prognosis group based on the pretreatment IBPS, moved to the good prognosis group following nivolumab administration. This result suggests that the same proportion of patients deemed to have a poor prognosis may manage to improve through nivolumab treatment. Regarding the NLR, Kim et al. have also suggested that the change in the NLR after ICI therapy might reflect the actual process of ICI-induced immune response (38). The role of an on-treatment increase in the NLR as a poor prognostic factor for ICIs was also reported in other cancer types, including melanoma, NSCLC, and renal cell 
carcinoma $(39,40)$. Our results are consistent with those of previous studies on malignant tumors. Meanwhile, we also have to acknowledge that some cases changed from good to poor prognosis following nivolumab therapy. These patients were not suitable for this treatment. We will accumulate more cases to delineate the type of patient corresponding to this pattern of behavior in future.

In the present multivariate analysis, regarding IBPS, the post-treatment factor was an independent prognostic factor in RMHNSCC patients treated with nivolumab. Our results suggest that pre-IBPS is not an adequate prognostic biomarker for RMHNSCC patients treated with nivolumab therapy. Based on the above results, we believe that the treatment outcomes of nivolumab can be predicted by testing clinical and routine laboratory factors soon after treatment (post-treatment IBPS).

Regarding measuring the IBPS prior to the anticancer drug therapy, Crumley et al. have reported that, specifically for GPS, it positively correlated with the frequency of side effects in patients with gastroesophageal cancer (41). IBPS may, thus, be useful for predicting the onset of AEs $(36,41)$. However, unlike other anti-cancer therapies, the occurrence of adverse events in patients treated with ICIs has been shown to be related to a good prognosis $(42,43)$. Our results are also consistent with those of previous studies. Thus, there may be little benefit in using the pre-IBPS to predict AEs.

Several limitations associated with the present study warrant mention, including its retrospective nature, the potential existence of selection bias, the small sample size, and the insufficient evaluation of AEs. Given these limitations, we believe that in the future, continuing to study the relationship between the IBPS and AEs and accumulating more data from large cohorts will aid in the construction of a more appropriate framework of precision medicine for patiesnts with incurable RMHNSCC.

In conclusion, our results suggest that the post-nivolumab GPS, NLR, CAR, and eosinophil count are significantly associated with survival outcomes in RMHNSCC, but not the pre-nivolumab IBPS. We believe that the IBPS is useful as a prognostic biomarker for RMHNSCC and can help guide subsequent therapeutic strategies for anticancer drug therapy.

\section{Conflicts of Interest}

The Authors have no relevant conflicts of interest to declare.

\section{Authors' Contributions}

Ryuji Yasumatsu, the corresponding author of the work, certifies that all Authors have participated sufficiently in the conception and design of the work. All Authors approved the final version of the manuscript and agree to be accountable for all aspects of the work in ensuring that questions related to the accuracy or integrity of any part of the work are appropriately investigated and resolved. Mioko Matsuo had full access to all the data in the study and takes responsibility for the integrity of the data and the accuracy of the data analysis, and wrote the manuscript. Ryuji Yasumatsu developed the study concept and design of the work. Muneyuki Masuda revised the work critically for important intellectual content. Satoshi Toh, Takahiro Wakasaki and Kazuki Hashimoto statistically interpreted the data. Rina Jiromaru and Tomomi Manako recruited patients and acquired data. Takashi Nakagawa drafted the work.

\section{References}

1 Vermorken JB, Mesia R, Rivera F, Remenar E, Kawecki A, Rottey S, Erfan J, Zabolotnyy D, Kienzer HR, Cupissol D, Peyrade F, Benasso M, Vynnychenko I, De Raucourt D, Bokemeyer C, Schueler A, Amellal N and Hitt R: Platinumbased chemotherapy plus cetuximab in head and neck cancer. N Engl J Med 359(11): 1116-1127, 2008. PMID: 18784101. DOI: 10.1056/NEJMoa0802656

2 Ferris RL, Blumenschein G Jr, Fayette J, Guigay J, Colevas AD, Licitra L, Harrington K, Kasper S, Vokes EE, Even C, Worden F, Saba NF, Iglesias Docampo LC, Haddad R, Rordorf T, Kiyota N, Tahara M, Monga M, Lynch M, Geese WJ, Kopit J, Shaw JW and Gillison ML: Nivolumab for recurrent squamous-cell carcinoma of the head and neck. N Engl J Med 375(19): 18561867, 2016. PMID: 27718784. DOI: 10.1056/NEJMoa1602252

3 Burtness B, Harrington KJ, Greil R, Soulières D, Tahara M, de Castro G Jr, Psyrri A, Basté N, Neupane P, Bratland Å, Fuereder T, Hughes BGM, Mesía R, Ngamphaiboon N, Rordorf T, Wan Ishak WZ, Hong RL, González Mendoza R, Roy A, Zhang Y, Gumuscu B, Cheng JD, Jin F, Rischin D and KEYNOTE-048 Investigators: Pembrolizumab alone or with chemotherapy versus cetuximab with chemotherapy for recurrent or metastatic squamous cell carcinoma of the head and neck (KEYNOTE-048): a randomised, open-label, phase 3 study. Lancet 394(10212): 1915-1928, 2019. PMID: 31679945. DOI: 10.1016/S0140-6736(19)32591-7

4 Biomarkers Definitions Working Group: Biomarkers and surrogate endpoints: preferred definitions and conceptual framework. Clin Pharmacol Ther 69(3): 89-95, 2001. PMID: 11240971. DOI: $10.1067 / \mathrm{mcp} .2001 .113989$

5 Patel SP and Kurzrock R: PD-L1 expression as a predictive biomarker in cancer immunotherapy. Mol Cancer Ther 14(4): 847-856, 2015. PMID: 25695955. DOI: 10.1158/1535-7163. MCT-14-0983

6 Boeck S, Jung A, Laubender RP, Neumann J, Egg R, Goritschan C, Vehling-Kaiser U, Winkelmann C, Fischer von Weikersthal L, Clemens MR, Gauler TC, Märten A, Klein S, Kojouharoff G, Barner M, Geissler M, Greten TF, Mansmann U, Kirchner T and Heinemann V: EGFR pathway biomarkers in erlotinib-treated patients with advanced pancreatic cancer: translational results from the randomised, crossover phase 3 trial AIO-PK0104. Br J Cancer 108(2): 469-476, 2013. PMID: 23169292. DOI: 10.1038/bjc.2012.495

7 Dolan RD, McSorley ST, Horgan PG, Laird B and McMillan DC: The role of the systemic inflammatory response in predicting outcomes in patients with advanced inoperable cancer: Systematic review and meta-analysis. Crit Rev Oncol Hematol 116: 134-146, 2017. PMID: 28693795. DOI: 10.1016/j.critrevonc.2017.06.002 
8 Dolan RD, Laird BJA, Horgan PG and McMillan DC: The prognostic value of the systemic inflammatory response in randomised clinical trials in cancer: A systematic review. Crit Rev Oncol Hematol 132: 130-137, 2018. PMID: 30447918. DOI: $10.1016 / j$.critrevonc.2018.09.016

9 Selzer E, Grah A, Heiduschka G, Kornek G and Thurnher D: Primary radiotherapy or postoperative radiotherapy in patients with head and neck cancer: Comparative analysis of inflammation-based prognostic scoring systems. Strahlenther Onkol 191(6): 486-494, 2015. PMID: 25583136. DOI: 10.1007/s00066-014-0803-1

10 Yang L, Huang Y, Zhou L, Dai Y and Hu G: High pretreatment neutrophil-to-lymphocyte ratio as a predictor of poor survival prognosis in head and neck squamous cell carcinoma: Systematic review and meta-analysis. Head Neck 41(5): $1525-$ 1535, 2019. PMID: 30597654. DOI: 10.1002/hed.25583

11 Rassouli A, Saliba J, Castano R, Hier M and Zeitouni AG: Systemic inflammatory markers as independent prognosticators of head and neck squamous cell carcinoma. Head Neck 37(1): 103-110, 2015. PMID: 24339165. DOI: 10.1002/hed.23567

12 Sun P, Chen C, Xia Y, Bi X, Liu P, Zhang F, Yang H, An X, Jiang $\mathrm{W}$ and Wang $\mathrm{F}$ : The ratio of C-reactive protein/albumin is a novel inflammatory predictor of overall survival in cisplatinbased treated patients with metastatic nasopharyngeal carcinoma. Dis Markers 2017: 6570808, 2017. PMID: 28676731. DOI: $10.1155 / 2017 / 6570808$

13 Takenaka Y, Oya R, Kitamiura T, Ashida N, Shimizu K, Takemura K, Yamamoto $\mathrm{Y}$ and Uno A: Platelet count and platelet-lymphocyte ratio as prognostic markers for head and neck squamous cell carcinoma: Meta-analysis. Head Neck 40(12): 2714-2723, 2018. PMID: 30102821. DOI: 10.1002/ hed.25366

14 Bardash Y, Olson C, Herman W, Khaymovich J, Costantino P and Tham T: Platelet-lymphocyte ratio as a predictor of prognosis in head and neck cancer: a systematic review and meta-analysis. Oncol Res Treat 42(12): 665-677, 2019. PMID: 31550732. DOI: $10.1159 / 000502750$

15 Nishikawa D, Suzuki H, Koide Y, Beppu S, Kadowaki S, Sone $\mathrm{M}$ and Hanai N: Prognostic markers in head and neck cancer patients treated with nivolumab. Cancers (Basel) 10(12): 466, 2018. PMID: 30477171. DOI: 10.3390/cancers 10120466

16 Nishikawa D, Suzuki H, Beppu S, Terada H, Sawabe M, Kadowaki S, Sone M and Hanai N: Eosinophil prognostic scores for patients with head and neck squamous cell carcinoma treated with nivolumab. Cancer Sci 112(1): 339-346, 2021. PMID: 33078505. DOI: $10.1111 /$ cas.14706

17 Mohammed FF, Poon I, Zhang L, Elliott L, Hodson ID, Sagar SM and Wright J: Acute-phase response reactants as objective biomarkers of radiation-induced mucositis in head and neck cancer. Head Neck 34(7): 985-993, 2012. PMID: 21953802. DOI: $10.1002 /$ hed. 21848

18 Douglas E and McMillan DC: Towards a simple objective framework for the investigation and treatment of cancer cachexia: the Glasgow Prognostic Score. Cancer Treat Rev 40(6): 685-691, 2014. PMID: 24321611. DOI: 10.1016/ j.ctrv.2013.11.007

19 Morita R, Okishio K, Shimizu J, Saito H, Sakai H, Kim YH, Hataji O, Yomota M, Nishio M, Aoe K, Kanai O, Kumagai T, Kibata K, Tsukamoto H, Oizumi S, Fujimoto D, Tanaka H, Mizuno K, Masuda T, Kozuki T, Haku T, Suzuki H, Okamoto I,
Hoshiyama H, Ueda J and Ohe Y: Real-world effectiveness and safety of nivolumab in patients with non-small cell lung cancer: A multicenter retrospective observational study in Japan. Lung Cancer 140: 8-18, 2020. PMID: 31838169. DOI: 10.1016/ j.lungcan.2019.11.014

20 Nakamura Y, Kitano S, Takahashi A, Tsutsumida A, Namikawa K, Tanese K, Abe T, Funakoshi T, Yamamoto N, Amagai M and Yamazaki N: Nivolumab for advanced melanoma: pretreatment prognostic factors and early outcome markers during therapy. Oncotarget 7(47): 77404-77415, 2016. PMID: 27764805. DOI: 10.18632/oncotarget.12677

21 Hori R, Shinohara S, Kojima T, Kagoshima H, Kitamura M, Tateya I, Tamaki H, Kumabe Y, Asato R, Harada H, Kitani Y, Tsujimura T, Honda K, Ichimaru K and Omori K: Real-world outcomes and prognostic factors in patients receiving nivolumab therapy for recurrent or metastatic head and neck carcinoma. Cancers (Basel) 11(9): 1317, 2019. PMID: 31500103. DOI: 10.3390/cancers 11091317

22 Sato H, Tsukahara K, Okamoto I, Katsube Y, Shimizu A, Kondo T, Hanyu K, Fushimi C, Okada T and Miura K: Clinical outcomes of platinum-based chemotherapy plus cetuximab for recurrent or metastatic squamous cell carcinoma of the head and neck: comparison between platinum-sensitive and platinumresistant patients. Acta Otolaryngol 139(2): 201-205, 2019. PMID: 30794080. DOI: 10.1080/00016489.2018.1551623

23 Forrest LM, McMillan DC, McArdle CS, Angerson WJ and Dunlop DJ: Evaluation of cumulative prognostic scores based on the systemic inflammatory response in patients with inoperable non-small-cell lung cancer. Br J Cancer 89(6): 10281030, 2003. PMID: 12966420. DOI: 10.1038/sj.bjc.6601242

24 Shibutani M, Maeda K, Nagahara H, Iseki Y, Hirakawa K and Ohira M: The significance of the C-reactive protein to albumin ratio as a marker for predicting survival and monitoring chemotherapeutic effectiveness in patients with unresectable metastatic colorectal cancer. Springerplus 5(1): 1798, 2016. PMID: 27812440. DOI: 10.1186/s40064-016-3529-y

25 An X, Ding PR, Li YH, Wang FH, Shi YX, Wang ZQ, He YJ, $\mathrm{Xu}$ RH and Jiang WQ: Elevated neutrophil to lymphocyte ratio predicts survival in advanced pancreatic cancer. Biomarkers 15(6): 516-522, 2010. PMID: 20602543. DOI: 10.3109/ 1354750X.2010.491557

26 Wu Y, Li C, Zhao J, Yang L, Liu F, Zheng H, Wang Z and Xu Y: Neutrophil-to-lymphocyte and platelet-to-lymphocyte ratios predict chemotherapy outcomes and prognosis in patients with colorectal cancer and synchronous liver metastasis. World J Surg Oncol 14(1): 289, 2016. PMID: 27852294. DOI: 10.1186/ s12957-016-1044-9

27 Sato H, Tsubosa Y and Kawano T: Correlation between the pretherapeutic neutrophil to lymphocyte ratio and the pathologic response to neoadjuvant chemotherapy in patients with advanced esophageal cancer. World J Surg 36(3): 617-622, 2012. PMID: 22223293. DOI: $10.1007 / \mathrm{s} 00268-011-1411-1$

28 Gooden MJ, de Bock GH, Leffers N, Daemen T and Nijman HW: The prognostic influence of tumour-infiltrating lymphocytes in cancer: a systematic review with meta-analysis. Br J Cancer 105(1): 93-103, 2011. PMID: 21629244. DOI: 10.1038/bjc.2011.189

29 Carretero R, Sektioglu IM, Garbi N, Salgado OC, Beckhove P and Hämmerling GJ: Eosinophils orchestrate cancer rejection by normalizing tumor vessels and enhancing infiltration of CD8(+) 
T cells. Nat Immunol 16(6): 609-617, 2015. PMID: 25915731. DOI: $10.1038 /$ ni.3159

30 McCourt M, Wang JH, Sookhai S and Redmond HP: Activated human neutrophils release hepatocyte growth factor/scatter factor. Eur J Surg Oncol 27(4): 396-403, 2001. PMID: 11417987. DOI: 10.1053 /ejso.2001.1133

31 Sharma D, Brummel-Ziedins KE, Bouchard BA and Holmes CE: Platelets in tumor progression: a host factor that offers multiple potential targets in the treatment of cancer. J Cell Physiol 229(8): 1005-1015, 2014. PMID: 24374897. DOI: 10.1002/jcp.24539

$32 \mathrm{Li} \mathrm{XH,} \mathrm{Chang} \mathrm{H,} \mathrm{Xu} \mathrm{BQ,} \mathrm{Tao} \mathrm{YL,} \mathrm{Gao} \mathrm{J,} \mathrm{Chen} \mathrm{C,} \mathrm{Qu} \mathrm{C,} \mathrm{Zhou}$ S, Liu SR, Wang XH, Zhang WW, Yang X, Zhou SL and Xia YF: An inflammatory biomarker-based nomogram to predict prognosis of patients with nasopharyngeal carcinoma: an analysis of a prospective study. Cancer Med 6(1): 310-319, 2017. PMID: 27860387. DOI: $10.1002 /$ cam 4.947

33 Kano S, Homma A, Hatakeyama H, Mizumachi T, Sakashita T, Kakizaki $\mathrm{T}$ and Fukuda S: Pretreatment lymphocyte-tomonocyte ratio as an independent prognostic factor for head and neck cancer. Head Neck 39(2): 247-253, 2017. PMID: 27617428. DOI: $10.1002 /$ hed 24576

34 Ikeguchi M: Glasgow prognostic score and neutrophillymphocyte ratio are good prognostic indicators after radical neck dissection for advanced squamous cell carcinoma in the hypopharynx. Langenbecks Arch Surg 401(6): 861-866, 2016. PMID: 27236289. DOI: 10.1007/s00423-016-1453-9

35 Turri-Zanoni M, Salzano G, Lambertoni A, Giovannardi M, Karligkiotis A, Battaglia P and Castelnuovo P: Prognostic value of pretreatment peripheral blood markers in paranasal sinus cancer: Neutrophil-to-lymphocyte and platelet-to-lymphocyte ratio. Head Neck 39(4): 730-736, 2017. PMID: 28032937. DOI: 10.1002/hed.24681

36 Mikoshiba T, Ozawa H, Saito S, Ikari Y, Nakahara N, Ito F, Watanabe Y, Sekimizu M, Imanishi Y and Ogawa K: Usefulness of hematological inflammatory markers in predicting severe side-effects from induction chemotherapy in head and neck cancer patients. Anticancer Res 39(6): 3059-3065, 2019. PMID: 31177149. DOI: 10.21873/anticanres.13440

37 Yasumatsu R, Wakasaki T, Hashimoto K, Nakashima K, Manako $\mathrm{T}$, Taura $\mathrm{M}$, Matsuo $\mathrm{M}$ and Nakagawa $\mathrm{T}$ : Monitoring the neutrophil-to-lymphocyte ratio may be useful for predicting the anticancer effect of nivolumab in recurrent or metastatic head and neck cancer. Head Neck 41(8): 2610-2618, 2019. PMID: 30835919. DOI: $10.1002 /$ hed.25737
38 Kim JY, Jung EJ, Kim JM, Lee HS, Kwag SJ, Park JH, Park T, Jeong SH, Jeong CY and Ju YT: Dynamic changes of neutrophilto-lymphocyte ratio and platelet-to-lymphocyte ratio predicts breast cancer prognosis. BMC Cancer 20(1): 1206, 2020. PMID: 33287745. DOI: $10.1186 / \mathrm{s} 12885-020-07700-9$

39 Möller M, Turzer S, Schütte W, Seliger B and Riemann D: Blood immune cell biomarkers in patient with lung cancer undergoing treatment with checkpoint blockade. J Immunother 43(2): 57-66, 2020. PMID: 31592989. DOI: 10.1097/CJI. 0000000000000297

40 Li M, Spakowicz D, Burkart J, Patel S, Husain M, He K, Bertino EM, Shields PG, Carbone DP, Verschraegen CF, Presley CJ, Otterson GA, Kendra K and Owen DH: Change in neutrophil to lymphocyte ratio during immunotherapy treatment is a nonlinear predictor of patient outcomes in advanced cancers. J Cancer Res Clin Oncol 145(10): 2541-2546, 2019. PMID: 31367835. DOI: 10.1007/s00432-019-02982-4

41 Crumley AB, Stuart RC, McKernan M, McDonald AC and McMillan DC: Comparison of an inflammation-based prognostic score (GPS) with performance status (ECOG-ps) in patients receiving palliative chemotherapy for gastroesophageal cancer. J Gastroenterol Hepatol 23(8 Pt 2): e325-e329, 2008. PMID: 17645468. DOI: 10.1111/j.1440-1746.2007.05105.x

42 Matsuo M, Yasumatsu R, Masuda M, Toh S, Wakasaki T, Hashimoto K, Taura M, Uchi R and Nakagawa T: Relationship between immune-related adverse events and the long-term outcomes in recurrent/metastatic head and neck squamous cell carcinoma treated with nivolumab. Oral Oncol 101: 104525, 2020. PMID: 31863963. DOI: 10.1016/j.oraloncology.2019. 104525

43 Ricciuti B, Genova C, De Giglio A, Bassanelli M, Dal Bello MG, Metro G, Brambilla M, Baglivo S, Grossi F and Chiari R: Impact of immune-related adverse events on survival in patients with advanced non-small cell lung cancer treated with nivolumab: long-term outcomes from a multi-institutional analysis. J Cancer Res Clin Oncol 145(2): 479-485, 2019. PMID: 30506406. DOI: 10.1007/s00432-018-2805-3

Received December 16, 2021

Revised January 27, 2022

Accepted January 31, 2022 